\title{
A Shifting Paradigm - Medical to Interactional Model: A Personal History
}

\section{Lawrence Shulman}

\begin{abstract}
This article chronicles over 50 years of change in the profession with an emphasis on the author's professional experiences and the shift in practice paradigms from the medical model to an interactional model. A number of key phases in this shift are identified and illustrated drawn from the author's work over time.
\end{abstract}

Keywords: Interactional model, medical model, paradigm shifts, William Schwartz

When I was asked to submit an "Eyewitness to History" article, I was at a loss as to how to approach it. After some reflection, I realized I had a personal and professional history that was closely tied to the development of what I describe as a paradigm shift in thinking about social work practice. I also had the advantage of being influenced by a number of mentors who themselves had significant roles in developing social work practice as we know it today. I decided to simply tell chronologically the story of my professional history, and as I did so, to connect my experiences to developments in social work and social work education during the 52 years since my 1961 graduation from the Columbia University School of Social Work (CUSSW).

In particular, I will focus on the events and activities that had a substantial impact on the development of the Interactional paradigm. The list below provides an overview of the sections that follow, each presenting a component of the paradigm shift:

- My MSW education at the Columbia University School of Social Work - Group Work and the Social Goals model

- First contacts with Bill Schwartz and my introduction to the Mutual Aid Model and a new paradigm.

- Defining a paradigm shift and the distinction between the Interactional and Medical Models

- The introduction of system's theory to social work education: The Agency as the "Second Client"

- Operationalizing and researching the Interactional Model

- The Functionalist approach to social work practice at the University of Pennsylvania - Contributions of Taft and Robinson

- Doctoral studies in Educational Psychology and my introduction to Category Observation and other research methods focusing on the process of practice as well as the outcomes.

- The parallel process in social work, supervision and teaching

Lawrence Shulman, Ed.D., MSW, is Professor and Dean Emeritus of the School of Social Work at the University of Buffalo in Buffalo, NY.

Copyright @ 2014 Advances in Social Work Vol. 15 No. 1 (Spring 2014), 207-229 
- The use of video tapes as a tool for dissemination of the Interactional Model

- Where do things stand now?

\section{Phase 1: The Early Days - MSW Education at CUSSW}

I was a "group worker" in those days which meant I went through Columbia with a cohort of 30 group work students. Most students at CUSSW were "caseworkers" and a few were "community organization students" (C.O.). In those days C.O. meant, in large part, fund raising for "Community Chests," now called United Ways. It wasn't until later that grass roots organizing, using the Saul Alinsky confrontation model, described in his book Rules for Radicals: A Pragmatic Primer for Realistic Radicals (1971), became associated with social work's version of C.O. The civil rights movement also had an impact on C.O. as did the emergence of organized welfare rights groups. However, the concept of generalist practice and a universal foundation practice course taken by all students was not yet part of our social work education model.

I was placed for my first year field experience at the Mt. Vernon Jewish Community Center in 1960. It was at this placement that I first met two influential thinkers in social work. George Braeger was the agency director and Harry Specht my field supervisor. ${ }^{1}$ George and Harry later left the agency to run the Mobilization for Youth project in New York City.

This was a 13 million dollar innovative program funded by President Kennedy based on Cloward and Ohlin's (1960) delinquency and opportunity theory. Mobilization for Youth, focused on expanding the legitimate opportunities afforded to young people in an effort to decrease delinquent behavior. Braeger wrote the proposal and directed the project and Specht helped to manage it. This project was seen as an application of the Cloward and Ohlin theory that contributed to the social reform movement that led to the war on poverty.

On reflection I realize I did not get strong supervision on my group work practice, but I did get a heavy and helpful dose of concern for social justice. I was exposed to George and Harry, and their views on the role of social work in my field placement, and similar thoughts in my CUSSW class on social issues taught by Cloward. While emphasizing a return to social work's classic historical mission, epitomized by Jane Adams and the settlement house movement, the model still borrowed from the medical paradigm. Only now, instead of diagnosing the client and developing an assessment and intervention plan, we would diagnose the social systems that impacted our client and intervene with them. The target was different however the three-step model was the same.

This was brought home clearly to me a few years later when, attending a conference presentation by Cloward, I challenged his endorsement of the use of manipulation and

\footnotetext{
${ }^{1}$ George went on to eventually become Dean of CUSSW and Harry to serve as Dean at the School of Social Work at Berkley University. George co-authored with Steve Holloway in 1978 the classic book Changing Human Services Organizations: Polities and Practice. Harry co-authored with Mark Courtney in 1993 their challenge to what they believed was social work’s loss of its historic mission titled Unfaithful Angels.
} 
indirect influence when working with a community action group. His response was that it might be necessary because the social worker knew what was best in a conflict situation and therefore was acting in the client's interest. The core paradigm of practice in which we might act on instead of act with the client had not really changed. Cloward did go on to make a major contribution in his advocacy of the "motor-voter" registration program allowing people to register to vote when they registered their cars.

\section{Phase 2: My Early Practice and How I met Bill Schwartz}

In 1964 when I returned to my first year field placement and began working at the Mt. Vernon Jewish Community Center, the social change oriented legacy shared by Braeger, Specht and Cloward was still strong in the agency culture. This orientation fit with the "Social Goals" model of group work taught at Columbia. In addition to recreation, a major purpose for leading groups in Y's, community centers and youth programs, where many MSW group workers worked, was to impart social work's historic values of democracy and social justice.

Returning now to the field instructor's seminar, the real start of this story, in our first session Schwartz asked each of us to share the assignments we had developed for our students. I proudly described a teen leadership group with which I was involved and a project where our teens joined with an African-American church youth group to raise funds for poor residents of color in Mt. Vernon. This was one of the groups in my social work student field assignment. I went on to point out that the real purpose of the group was to improve black and white relationships in Mt. Vernon, a town experiencing a rapid growth in the number of poor families of color and the beginning of "white flight."

I remember to this day Bill Schwartz looking directly at me and asking: "Do your group members know the real purpose of the group?” I felt confused and embarrassed. Wasn't this what my social goals model taught me as the job of a group worker? I remember little of the remainder of the session. I arrived home that night and told my wife I was so mad I was not going back to the seminar. After cooling down, and with some reflection, I realized Bill's question had been reasonable. We believed in "informed consent" but how could the group members be fully informed and give consent if we had a "hidden agenda." I experienced this as a "light going on," raising questions about all of my group practice and supervision of our part-time group leaders. Most of our discussion in supervision was about how to impact the group using program (activities such as games, trips and social events) as it had been in my own supervision as a field student.

The teen project was a good one. When it was initiated, I could have suggested it to the group members, involved them in the planning, and acknowledged the goal of impacting race relations in Mt. Vernon. I was unable to answer the question of why I had not done just that. Later I realized it was an issue related to the paradigm that guided my practice and the field of social work as well. In some ways, as you will see later in this chapter, I believe that this remains true in some respects for social work today.

I returned to the seminar and over the years Bill became an important mentor for my practice, teaching and research. Thus began my sometimes painful paradigm shift from the Medical Model toward what I now call the Interactional Model. 


\section{Phase 3: Paradigm Shifts, Social Work, Group Work, and the Medical Model}

Thomas Kuhn, in his influential book The Structure of Scientific Revolutions (1962), discussed changes in science that occurred not by increment but by revolution. The classic example is the change from Ptolomy's astronomy paradigm which placed the earth at the center of the universe to the heliocentric model advocated by Copernicus in the $15^{\text {th }}$ century, which placed the sun, rather than the earth at the center. Kuhn pointed out that such dramatic shifts often meet strong opposition. He also pointed out that new paradigms continue to emerge often building on the old ones as they replaced them. For example if one thinks of astronomy, there was Einstein and the theory of relativity. More recently we have seen astronomy theories based on black holes, quirks and quarks, etc. These build on previous paradigms and may be gradually accepted because they offer explanations for the old paradigm's anomalies.

Anomalies are unexplained events or findings that do not fit the established paradigm. For example, the sun, moon and other celestial bodies might move across the sky in ways not explained by the predominant, at the time, earth-centric paradigm. (For the Medical Model I believe a significant anomaly was client non-compliance with perfectly sound treatment plans.) Kuhn also believed that the social sciences were not "scientific" enough to have paradigms and shifts. On this point, I disagree.

\section{Social Work and the Medical Model}

The Medical Model is often used in social work literature to describe a pathologyoriented approach to assessing and diagnosing clients. Alternatives are offered by many newer models such as the "strengths perspective" and a "systems approach" both of which largely reject the pathology model for assessment and diagnosis. This is not the medical model to which I refer.

The Medical Model challenged by the Interactional Model is based on the three (now four) sequential steps of thinking about social work practice: Study, Diagnosis, Treatment and Evaluation, cycling back to "study" should the evaluation indicate the need. This is the model that social work and other helping professions borrowed from medicine. It had become crucial to the medical profession's early efforts to distinguish itself from other healing professions and to establish itself as "scientific."

Please understand that I am not raising questions about the elements of study (gathering information) or diagnosing (attempting to understand the nature of the client's problem or issue) or treatment (developing and implementing plans for intervention in collaboration with the client). The challenge is not to the individual elements of the Medical Model but rather to the three-step sequential description contained in the paradigm. $^{2}$

In contrast, one of the essential differences in the Interactional paradigm is the understanding that the worker-client interaction is dynamic, with each actor impacting the

\footnotetext{
${ }^{2}$ At one school I taught during these early days, case work students spent their first year in practice class working on "study" and moved to "diagnosis" and "treatment" only in the second year.
} 
other moment-by-moment in the individual interview, family session, group or community setting. Treatment does not wait for the diagnosis since the conversation with a client in the first session is actually the start of an intervention and the helping process. Also, no matter what the diagnosis, treatment or intervention planned with colleagues or with the supervisor in the case conference, the social worker will be strongly influenced, often emotionally, by the responses of the client. That in turn will affect the interaction and so forth. Social work practice does not proceed in the neat and orderly manner described in the Medical Model.

Another example of the paradigm shift involves the separation of the worker's feelings and his or her professional interaction with clients. This separation was advocated in most social work education then, and is still advocated by some today. I refer to this as the personal/professional dichotomy. The need to maintain a separation between the two was also borrowed from medicine. In my early research, practice and teaching I found that professional versus personal was a false dichotomy in that effective practice involved learning how to integrate the personal and professional. The Interactional Model suggests that the social worker needs to "use" his or her feelings not "lose" them.

I should make clear this does not give permission for the social worker to act out. Rejecting the false dichotomy does not allow the worker to express any and all feelings of the moment. Affect must be integrated with the professional purpose and role. For example, a common issue raised in my workshops by child welfare workers who are not parents is the emotional challenge they feel when a client, a mother of three for example, inquires as to how many children the worker has. Defensive responses such as: "We are here to talk about you, not me!" or "I have none but I have taken courses in child psychology at the school of social work" miss the meaning of the question which often is "Can you understand what it is like for me?" or "Can you really help me?" or "Are you going to judge me?”

A worker who is "tuned in," develops preliminary empathy to the meaning of the question and responds directly, with genuine empathy, saying, for example: "I don't have any children. Why do you ask? Are you concerned I may not understand what it's like for you? I'm concerned about that as well. If I'm going to help I have to understand you will need to tell me." This or some version of this is an example of integrating personal and professional. A simple expression of what the unprepared worker may be feeling, such as: "You're right! I don't have kids. How do they expect me to help you?" is not an integration of personal and professional. Those feelings need to be shared with the supervisor.

This dichotomizing of personal and professional, borrowed from medicine, does not work well for doctors either as the emergence of "behavioral medicine" has emphasized. In a study I carried out with 54 family physicians in Vancouver, BC in 1982, I asked doctors, among other variables, to rate their attitudes toward specific patients - positive, 
neutral or negative - immediately after seeing the patients. ${ }^{3}$ The study explored the impact of the physician's communication, relationship and technical skills on patient compliance, satisfaction, reassurance, comprehension and improvement (Shulman \& Buchan, 1982).

In interviews conducted by research assistants with 603 patients at the doctor's office immediately following the visits, we asked among other things about the patients' perception of their doctor's attitude toward them. We found a correlation between the two ratings. In discussions of these findings, doctors were surprised and often indicated they were sure they had hidden their negative feelings, just as social workers may feel they do as well. However, many patients (and clients) have powerful emotional radar and are able to detect these feelings. In our study, using data we obtained immediately following the visit and by phoning the patient one week later, we found that the doctor's attitude toward the patient - positive, neutral or negative - had an impact on outcomes such as patient relationship, compliance, satisfaction and comprehension.

For some in the helping professions, just as in astronomy, the old paradigms have too strong an influence and do not allow them to see practice from a strikingly different perspective. The well-known Gestalt drawing of an old woman who, when the viewer's perception shifts, becomes a young woman illustrates the dynamic. You can't see both the old and young women at the same time. It's necessary to let go of one in order to see the other. When I used this drawing in a class, some students were not able to let go of their first perception of the old or the young lady just as social workers may practice using the medical model, as defined here, and don't realize they are guided by that paradigm.

Agency intake procedures, with forms that must be completed for insurance purposes, can occupy a first session. This displaces a contracting process that seeks to clarify the purpose of the encounter, clarify the role of the social worker, reach for feedback on the client's perception of need, and address issues of authority and confidentiality. These are interventions that are part of the "contracting" process in the beginning phase of practice that may be given less attention while the social worker obtains data. ${ }^{4}$ Many social workers have described to me how the pressure of obtaining "billable hours" or finding themselves supervised by other disciplines (e.g., social workers supervised by nurses in medical settings), forces them to skip the step of engaging the client in the first session.

Implementing these contracting skills at the start of the engagement process actually begins to build the "working relationship," now termed the "therapeutic alliance" in the literature. When the intake of information is required by the agency or other setting, I encouraged my students to find a way to do both, pointing out that much of the needed information will come out in the contracting conversation. In addition, the data gathering

\footnotetext{
${ }^{3}$ Foundation funding for this study allowed me to serve full-time for one semester as a scholar in residence in the University's family practice center. I met weekly with a group of family practice residents and site faculty and reviewed video tapes of their contacts with patients.

4 These skills and others are elaborated and illustrated in my books and articles including The Skills of Helping Individuals, Families, Groups and Communities, $7^{\text {th }}$ edition, 2012.
} 
can be completed in the second half of the session. The central argument is that "treatment" actually begins when the client enters the office, not after a detailed study, and assessment, diagnosis and a treatment plan has been completed.

\section{Phase 4: The Social Worker in the Group}

Schwartz's major publication on this subject was an article published in 1961 titled "The Social Worker in the Group.” It was a compression of his educational doctoral thesis that laid the groundwork for what was later termed the "Mediating Model." This term was inferred by social work authors Catherine Pappel and Beulah Rothman (1966) because of the role of the group worker, as described by Schwartz, in mediating the engagement between the individual and the group. Schwartz never accepted the term "Mediating Model"; however, the title has been widely used along with the Social Goals and the Remedial Model, based on behavior modification concepts. This came to be known as the trio of approaches to group work practice. Another term used by some to describe Schwartz's approach was the "reciprocal" model based on the notion that between members of the group and the group leader there was an element of reciprocity in the relationship.

A more accurate term for Schwartz's approach would have been the Mutual Aid Model since at the core was the concept of the group leader helping members to help each other. The mutual aid concept was based upon the belief that the central relationship between people, the individual and the group (or family) or the individual and society, was symbiotic in nature. This relationship was often obscured by obstacles that prevented group members and people in general from seeing their common ground. The group for Schwartz was an "enterprise in mutual aid" and the role of the leader was to help the group members to discover and act on their need for each other. For example, the "all-inthe-same-boat" phenomenon, in which group members discover they are not alone, came to be seen as a supportive and healing process. ${ }^{5}$

This was a departure from the Medical Model in which the group leader was someone with authority who would structure the group and influence the interaction to change the member's values (social goals model) or behavior (remedial model). A major tool used by group workers at that time was the use of activity specifically selected and designed to have an influence on group members, again often without their knowledge. For example, a group worker might select an activity for a children's group that would allow a scapegoated child to excel thus indirectly attempting to influence and diffuse the scapegoating process. This intervention could fit within the social goals or remedial model approach to practice.

This contrasted with an article I published in Social Work in 1967 ("Scapegoats, Group Workers, and the Pre-emptive Intervention") which tried to understand the scapegoating process as a dynamic interaction in the group in which group members projected onto the scapegoated member some of their own doubts, concerns and feelings

\footnotetext{
${ }^{5}$ I attempted to inventory and illustrate a number of mutual aid processes in "The Dynamics of Mutual Aid” which was a chapter in a collection of articles by Schwartz and many of his former students entitled The Legacy of William Schwartz: Group Practice as Shared Interaction (Gitterman \& Shulman, Eds., 1986).
} 
about themselves. ${ }^{6}$ This was consistent with the biblical interpretation in which the sins of the people were projected onto the "scape" (skin) of a goat that was then sent out into the wilderness to die taking the mortal sins with them, at least for that year.

In the article, I urged group leaders who naturally experience protective feelings toward the scapegoat not to side with the group or the scapegoated individual, but rather to see the group as the "second client" calling for help through the process of scapegoating. The significant paradigm change was that the scapegoating was not a behavior to be changed but rather seen as a message to the group leader by the scapegoating group members. By addressing the "meaning" of the behavior, the group leader was helping members deal with their own sense of low self-esteem. The group would no longer need a scapegoat. In theory, the scapegoat would no longer need to "volunteer" for the role.

The "pre-emptive intervention," a term borrowed from the card game bridge, for example siding with the scapegoat, pre-empts the important work that needs to be done by the group members. Central to the mutual aid process is the idea of getting help by giving help. In the diagnostic framework of the time, one that is still referred to in social work and counseling publications today, the role of the group leader was to select the right activity (treatment) to help the scapegoated child and stop the process, rather than explore its meaning helping the individual and the group.

\section{Phase 5: Operationalizing and Researching Practice Intervention}

A position as a full-time faculty member at the Rutgers University School of Social Work opened up the next phase of my work at understanding, researching and writing about the Interactional Model. ${ }^{7}$ My position at Rutgers involved leading a field unit of 6 MSW students placed in a large New Jersey institution for what was then referred to as "mildly retarded" teen agers with behavioral problems. Meeting regularly with the 6 group-work students, I required them to write process recordings of their work with groups and also of their significant interactions with staff. The institution had a semimilitary culture with house staff concerned mostly with keeping order and keeping the teenage boys away from the girls.

The two years I worked in this position had a significant impact on my developing ideas about the importance of identifying and measuring practice interventions and also on the concept of viewing the agency as the "second client." My efforts to help my students develop the skills and interventions needed to work with their groups forced me to operationalize what they were doing. I needed the words to describe these interventions and to teach them consistently. This was the next step in identifying

\footnotetext{
${ }^{6}$ This article led to my over 40 years of friendship and collaboration with Alex Gitterman, the co-author with Carel Germain of The Life Model of Social Work Practice (1980). Attending a conference and meeting me for the first time, he invited me to be a fourth in a bridge game since I had used bridge in the article. He was surprised to hear that I had no idea how to play bridge. This was the beginning a wonderful friendship and professional collaboration.

${ }^{7}$ I should point out that the term Interactional Model was one I used later in my work since I think it more accurately described the broader paradigm of which the mutual aid model of group work was one example.
} 
behaviors that put the "mediating" functional role of the social worker, in individual and group practice, into action.

I came to more fully understand this task a few years later in 1973 when Joel Fisher, who later became a good friend and colleague, published a controversial article entitled, "Is Casework Effective?" Joel had reviewed social work research on the effectiveness of practice. The findings indicated that social work was not effective. This was an example of a paradigm "anomaly." All of the reported research projects were outcome studies in that they looked at the results of intervention models (e.g., family practice, group work, particular intervention models) but did not operationalize the independent variable, that is, what the social worker actually did when working with the client. If we could not clearly distinguish the "predictor" variable of practice we could not know, for example, if some social workers interacting in certain ways were actually very effective. Other social workers in the same study might, through their use of less effective interventions, offset the positive findings.

I realized that the real question, and the subject of needed research, was an answer to the question: "What is casework?" not "Is Casework Effective?" This became a required step when I later researched the impact of specific interventions. Outcome measures were, and still are important; however, I believed that as a profession we needed to first operationalize the "independent" variable at the level of specific worker skills. I also came to understand that there would be mediating or intervening variables - such as the development of a working relationship - now referred to as the therapeutic alliance in the literature - that would then influence outcome measures. Rosenberg's work in sociology (1968) on third variable analysis was helpful to me at that time.

\section{Phase 6: The Emergence of Social Systems Theory: The Agency as the Second Client}

My other significant learning as a full-time field instructor was my growing understanding that one could not practice within a setting, such as the institution housing my field unit, without using a dynamic and interactional perspective in which the "environment" was affecting the group, and the group in turn was affecting the environment. For me, this was the beginning of the concept of the setting as the "second client," and the use of an "organismic" model with the group and the setting seen as dynamic systems. Early organizational theory had often used a "mechanistic" model with "input," "through puts" and "outputs" central to the framework. A shift to the organismic model considered the organization as an organism with the ability to change, to grow, and to interact with its environment.

This understanding was crystalized for me by an incident involving a conflict between our student run program and the residential staff of the agency. The staff members, most of whom were middle age or older adults, former police or correction officers or army veterans, were responsible for the behavior within the dormitories. Monitoring and restricting behavior and discipline using rewards and punishment was their basic job. 
On a Monday morning, at my usual student unit meeting, one of my field students reported that the housing department had cancelled all social activities planned by my students and their group members. There had been an incident on Friday evening. After a structured and chaperoned party, as the teen boys walked their girlfriends back to the girls' dormitory, they kissed them goodnight on the dormitory steps while the other girls in the residence hung out the windows shouting encouragement and advice. The dormitory staff experienced this as a minor uprising and the solution was to ban all future parties planned by my students. I didn't realize at first that this was actually a deeper organizational response to our work which was challenging the existing culture of the agency.

My first reaction was anger at the staff group dictating what my social work students could or could not do. The parties were an important part of the social developmental work of these teenagers who were otherwise kept completely separate from each other. As we discussed this in the student unit meeting my thinking shifted to trying to understand the meaning or the message of the staff reaction. We had learned to understand our clients' "deviant” behavior as signals they were sending of underlying feelings and issues. Was the housing staff of the institution sending one to us? Was this a signal of issues for the entire staff and residents in an institution that had been run from the top down with little consultation or involvement with others? Could we apply principles we were using to describe the group process to a larger entity, the institution with the residential staff as one sub-group?

This was a breakthrough both for me and my students in our thinking about the social work role. Using contacts I had developed with heads of all of the departments (social work, housing, psychology, job training) ${ }^{8}$ I suggested we meet to consider the impact of our program on their work and what, if any, problems we were causing other staff. I was amazed at the number of department heads and staff who showed up at the meeting, which also was attended by my MSW students. Word of the meeting had spread throughout the institution with some expecting it to be a confrontation.

Applying the skills we had identified in working with the residents to our interaction with staff, skills I now refer to as the skills of professional impact, the students and I acknowledged the problems we may have caused in the system in a non-defensive manner. This diffused the negative tone of the meeting and the discussion shifted from our program's impact on other departments to the minimal influence of all staff on the running of the institution.

In hindsight after the meeting, we understood that the reaction of the housing staff was a signal of their feelings about their lack of influence in the system. We have learned to understand that in dynamic systems (e.g., families, groups, organizations) the members that experience the stress and feelings most strongly take on the role of acting them out. Housing staff did not have professional degrees, or college degrees, and were seen as

\footnotetext{
${ }^{8}$ I also learned the importance of developing informal relationships in a system. All of the department heads liked to play ping pong in a staff lounge during lunch. In the first few months of our unit's involvement, I had developed friendships through ping pong competition that were important to the success of my first efforts at organizing.
} 
"low status" in the staff system. No wonder they took on the role of acting out the feelings of impotence experienced by most of the other staff. ${ }^{9}$

After meeting with the institution's Superintendent in which I outlined the issues in a manner designed not to make him feel defensive, and then proposed steps we could take to improve morale and the staff's sense of involvement, we obtained his approval to go ahead with a plan that involved setting up cross-department staff groups addressing identified issues. My social work students worked as the "staff" for the staff groups, keeping minutes, etc. We were not yet at the stage where we could invite residents; however, the establishment of resident councils was one of the end results of this work. What was clear to me was that staff did not feel empowered and thus were not able to empower residents. ${ }^{10}$

I decided to write about my experiences in a monograph entitled, A Casebook of Social Work with Groups, published in 1968 by the Council on Social Work Education. The publication included the operationalizing and illustrating of a number of practice skills, critically analyzed process recordings and a discussion of the concept of the "setting" as the second client. Up to that point, the Council had published individual process recordings that social work faculty could purchase and use with their classes. This was the Council's first publication of an integrated monograph containing theory and process recordings. It was well received in the field and for years was one of their best-selling publications.

At about the same time, Gordon Hearn, a Canadian social work educator, was exploring the implications for social work of social systems theory, which had first emerged in sociology. This theory drew upon the "general systems theory" of von Bertalanffy and others. At the core were universal principles which could apply to systems at many different levels, such as a small group, a family and a large institution.

My casebook came to Hearn's attention and I was invited to present as part of a panel assembled for a national social work conference. This led to the inclusion of a chapter I wrote entitled "Social Systems Theory in Field Instruction" in Hearn's ground breaking book entitled Social Systems Theory in Social Work Education (1969). While the idea of using systems theory seems obvious today, it was not so obvious at that time. Social work education had required courses on human behavior, most with a psychoanalytic orientation. Not yet widely developed was the idea of teaching courses addressing human behavior within the social environment (HUBSE) as we now do.

\footnotetext{
${ }^{9}$ This concept has been useful in my work as a consultant on supervision and management when I have worked with large organizations. For example, when a hospital is under stress generally because of reduced funding one often finds the problems are acted out in the emergency room or other high stress departments. In a sense, they are acting for the institution as-a-whole.

${ }^{10}$ As a resolution of the issue that triggered this process, the residents demonstrated self-empowerment. It was agreed that they could kiss each other goodnight but not on the dormitory steps. A stop sign was designated as the boundary. The second rule was that they had to keep walking. On a Monday after the first party my student reported that they had stopped at the stop sign but remained there, kissing each other, while walking in place.
} 
While social systems theory was not inherently connected to the Interactional Model, it provided a theoretical structure for understanding both our practice in a group, the interactive nature of practice with worker and client constantly and immediately affecting each other, and the role of the profession in dealing with the setting and community as the second client. One could conceptualize a "boundary" surrounding the group, which was an open systems boundary with influence in both directions.

\section{Phase 7: The University at Pennsylvania and the Functional Approach to Practice}

The next stage of my professional development came when I left Rutgers and accepted a position as a lecturer at the University at Pennsylvania's (U of P) School of Social Work. My new appointment was controversial since I was the first recently hired full-time practice teacher who had not been a graduate of the $U$ of $P$ program. A new Dean, a social policy professor, had been appointed and the University insisted that the "in-breeding" of practice faculty had to stop. ${ }^{11}$ Some insight into this issue and its impact on development of the Interactional Model may be helpful at this point.

Although not a $\mathrm{U}$ of $\mathrm{P}$ graduate, I felt comfortable with the basic principles of the functional approach. Schwartz had borrowed major concepts from two former faculty members - Virginia Robinson and her partner Jessie Taft. Taft and Robinson had been psychoanalyzed by Otto Rank who developed the "Rankian Approach" to therapy which I won't describe in detail here other than to mention that "birth trauma" and the concept of "will therapy" were considered important. Will therapy emphasizes "conscious will" and its impact on behavior as opposed to the Freudian emphasis on the unconscious. Rank had been a Freud disciple but had broken with Freud and was afterward marginalized by the psychoanalytic profession.

Taft was analyzed by Rank in New York in 1926. Taft and Robinson had rejected the medical model, without calling it that. Instead they adopted a Rankian functional approach. The U of P SSW became the center for this model and the school itself ultimately was marginalized by the profession, which was still very much committed to Freud, psychoanalysis, and the Medical Model.

My early exposure to the marginalization of the $\mathrm{U}$ of $\mathrm{P}$ and the functional school was as an undergraduate in a course taught by a social worker. He provided an inaccurate and ridiculing characterization of the difference between the "functional approach" and the "diagnostic approach": "If a social worker was standing on a beach and a swimmer was clearly drowning, the diagnostic social worker would make the assessment and would swim out and save the swimmer. The functional social worker would wait until the swimmer asked for help.”

More serious isolation of the functionalist model and scholars by the mostly diagnostic oriented field included excluding $\mathrm{U}$ of $\mathrm{P}$ faculty from presenting at conferences or publishing their articles in scholarly journals. This may partially explain

\footnotetext{
${ }^{11}$ This Dean died three weeks after I started my appointment which explains, in part, some of the difficulty I experienced at the school without my "protector."
} 
why the school turned inward and hired only its own graduates to teach practice, at least until my appointment.

Elements of the work of Taft and Robinson incorporated by Schwartz into his model included the importance of affect and the impact of time. The feelings of the client (not the worker in the functionalist model) were very much a part of the helping process and needed attention. The concept of the phases of work - beginning, middles and endings with the preliminary phase added by Schwartz, drew on the functional literature. Many of the disciples of Taft and Robinson went on to teach and publish an approach to practice, while not the Interactional Model nevertheless focused on the interaction between the social worker and the client. The functional approach was in part an important predecessor of the Interactional Model.

I had assumed I would feel at home in this school since my writing and teaching had a strong functionalist theme. I soon discovered that while the group work sequence in which I taught described its approach as functional, as elaborated by Helen Philips (1957) a major figure in the field whom I replaced at the school, the actual paradigm in U of P group work was still diagnostic. Although the functional terminology was used, students were taught to assess the needs of the group members, diagnose the problems, and develop treatments (usually activities) without ever using these terms.

The problem of disciples not evolving and building on the theory of the founders, Taft and Robinson, was also evident in the notion of the agency as a "given," one not to be challenged. It was the client's willful struggle against the agency's function during the exchange with the social worker that would lead to change. It was the social worker and the agency on one side and the client on the other. Fresh off of my systems theory thinking and the publication of my casebook, I taught a model in which the social worker considered the agency as the second client and, as such, would remain open to systematic and skillful intervention directed toward potential agency change. The social worker in the mediation function as described by Schwartz would try to have professional impact on the agency to make sure it was effectively meeting the needs of the clients. The social worker was a "third force" between client and systems including the agency and was not overly identified with the agency versus the client.

This was a significant rejection of a core functional concept, and was being taught by this new faculty member (myself), a non- $U$ of $P$ graduate, who was hired over the objection of many on the practice faculty. The response to my "heresy" was brought home when the students invited me to present at one of their lunch time discussion groups. My topic was to be "Social Work Impact on the Agency as a System." These lunch time discussion groups were usually well attended by students and faculty; however, my heretical topic led to a planned boycott with not a single faculty member attending. This experience along with my not receiving a promotion to Assistant Professor after my two years at the school, despite positive teaching evaluations and more 
publications than most other faculty, was the signal that shifting paradigms would not be that easy. ${ }^{12}$

\section{Phase 8: Doctoral Studies, Research Methodology and the Move to McGill University}

At the end of my second year of teaching at $U$ of $\mathrm{P}$, I was offered a position at the School of Social Work at McGill University in Montreal. My disappointment over not receiving what I believed was a deserved promotion led me to accept this offer in 1969. The fact that my wife was a Canadian who grew up in Ontario also affected my decision.

During my two years in Philadelphia, I had attended an evening and summer parttime doctoral program in Educational Psychology offered at Temple University. The Temple program was attractive to me because of a specialization in group development and counseling. This provided an opportunity to study many of the foundational thinkers and revolutionaries cited in Schwartz's writing, including John Dewey, George Herbert Mead, Martin Buber, Talcot Parsons, Mary Follett and others who were not part of my original social work education (Schwartz, 1986).

In addition, the strong research component in this program allowed me to begin to develop the tools that I later would use in my practice research. At that time many if not most practice teachers in schools of social work, at least those I knew, did not have doctorates. Social work faculty who had PhDs tended to teach in policy, research, or human behavior and the social environment. Practice teachers came from practice settings which was their strength but also limited the amount of practice research done by practitioners. This may partially explain the focus on outcomes (the dependent variables) versus the nature of practice itself (the independent variables) by practice researchers.

Another advantage of my educational psychology doctorate was that the education field was conducting extensive research using category observation systems. These systems involved the development of categories of teacher and student behavior and then the analysis of the teaching, through observation or from videotapes. The numeric entries categorizing the behavior every number of seconds (e.g., five in one system) could then be entered onto punch cards and delivered to the main frame computer for analysis, with a printout available hours or days later. (Yes, a far cry from current technology; however, this all predated the use of the personal computer).

Education was clearly ahead of social work in its interactional analysis research with as many as 70 different systems outlined in Simon’s book, Mirrors for Behavior (1967), which was an anthology of observational instruments. In my judgment at the time, many of these systems were based on overly simplistic underlying educational theory so that the researchers reported the obvious. One system, the one developed by Amidon and Flanders (1963), seemed different with a structure and categories that more closely paralleled those I would want to explore.

\footnotetext{
${ }^{12}$ A number of years later, when the school had undergone significant changes in its leadership, curriculum and faculty, I was given an award by the school and invited to be the speaker at a well-attended meeting on the shifting paradigm and the functional approach.
} 
I used this framework to develop my own interactional analysis tool for classroom teaching. My doctoral dissertation research examined teaching at the university level. My plan was to implement a study at McGill University in Montreal where I now was teaching.

Once again, it's interesting how seemingly chance factors can have an important impact. In my first semester at McGill, I became a social friend with another American ex-patriot, the director of McGill's Instructional Communication Center (ICC). This Center had sophisticated video equipment and studios for use by McGill faculty. A second ex-patriot, also a social friend, was working in McGill's Center for Learning and Development (CLD). This Center's mission was improving teaching at the University. In my second year at McGill, I served for one semester as a full-time visiting scholar at CLD conducting workshops on teaching for faculty from many McGill schools and departments.

This system was adopted by the University and a funded project allowed faculty members to sign up for the videotaping of one class and to have a questionnaire on teaching effectiveness, also developed as part of my doctoral research, distributed to their students. They would then meet with a CLD consultant to review the interaction analysis print out as well as the student questionnaire data. The video tapes were time coded, as were the printouts, so the consultant and faculty member could select sections of the video for deeper analysis and discussion. This was a popular tool used for a number of years by some of the best teachers in the University as well as those who were new to teaching and by some who received negative teaching evaluations.

This work laid the groundwork for my later interactional analysis research into social work individual and group practice in two Canadian child welfare agencies, one in Montreal and one in Ottawa. This project was funded by the Canadian Government and involved videotaping and analyzing 120 hours of social work practice, 60 hours of individual sessions and 60 hours of group sessions. The videos were coded by trained and validated research assistants entering a number every three seconds that described the interaction they observed. We had over 100,000 coded entries.

For example, the number 10 represented three seconds of silence. A software program developed for the project would pair the first coder entry with their second, their second with their third, the third with their fourth, and so on. The print out provided a crude sense of interaction which allowed us to determine, for example, how long silences lasted and whether or not the client or the worker broke the silence. In another example, we could also determine whether or not the worker, in our judgment, was responding to the client's concerns or missing them completely. One interesting finding was that in the face of 3 seconds or more of silence the worker often intervened and at times did so by changing the subject.

We were also able to analyze the sessions according to rough estimates of time - the first (beginning), second (middle) and third (ending and transitions) segments. Understanding the impact of the phases of work in a single session was an important subject for the Interactional Model. We found that many workers were not responding to the direct or indirect "offerings" of the clients in the first third of the sessions, something 
we termed the lack of "sessional contracting." They were missing each other like ships in the night. This was often due to the worker having his or her own agenda determined by the treatment plan developed after completion of the study and diagnosis steps.

In addition the research included questionnaires completed by the clients, workers and their supervisors. We were exploring twenty-seven distinct social work skills. Research assistants also examined the client files to rate outcomes, such as stability of homes, days in foster care, etc. This analysis helped us to find answers to the earlier posed question: "What is practice?" as well as "Is practice effective?"

The first sharing of the results of this study in 1978 was an article in Social Work entitled, "A Study of Practice Skills." The findings were integrated into the first of seven editions of The Skills of Helping Individuals and Groups (1979). ${ }^{13}$ The results of this project were also jointly published in 1981 by the Council on Social Work Education and the Canadian Association of Schools of Social Work in a book entitled, Identifying, Measuring and Teaching the Helping Skills.

For a number of years my publisher, Peacock Press, had been producing a successful book on generalist practice (Pincus \& Minahan, 1973) that integrated a social system perspective but within the medical model. This widely used textbook described social work practice at a more theoretical and abstract level and referred to "change agent systems," "client systems," "target systems" and "action systems." The authors drew upon family systems practice which was evolving to recognize the interactive nature of members of a family and the family's relationship to the environment. Examples were included, but most often they were observations about the problem in a particular system and did not include process recordings that would focus on the specific social worker interventions.

I believe the positive response to the Pincus and Minahan book and to the espoused model related in part to the rapidly spreading shift to generalist social work practice in schools of social work. Schools that formerly organized according to method, casework, group work and community work, were rapidly moving to teaching a generalist approach in the first year (MSW and BSW) and then using a specialization approach in year two. For some schools year two was method organized (e.g., individual, family, group and community) while for others it was field of practice (e.g., child welfare, medical). A first year practice book at this higher level of abstraction could be used to describe a generalist practice model within the diagnostic Medical Model.

The 1979 publication of the Skills of Helping Individuals and Groups was an important transition time in the wider dissemination of the Interactional Model. This book was adopted by many faculty members for first year generalist practice courses and according to my publisher, Peacock, was replacing the sales of the previously widely used text by Pincus and Minahan. I would mark this period and the years that followed as the beginning, for some social work educators and practitioners, of the paradigm shift.

\footnotetext{
13 The editions expanded over the years with the $7^{\text {th }}$ published in 2012 titled, The Skills of Helping Individuals, Families, Groups and Communities, thus applying the Interactional Model to a full range of practice modalities.
} 


\section{Phase 9: A Study of the Parallel Process}

In 1974 I moved to the University of British Columbia in Vancouver. This marked the beginning of 10 years of research into child welfare practice, supervision, management, teaching and the doctor-patient study mentioned earlier. With significant private foundation funding I was able to expand and replicate over a three-year period the previous study of practice but this time across 10 regions of the Provincial Ministry of Human Resources.

Participants in this project included 5 Ministry Executive Directors, 10 Regional Managers, 68 District Office (front-line) Supervisors, 175 social workers and 53 family support workers. Practice with 305 families (449 children) was studied over a three-year period. The central focus of the study was the impact of the use of a number of specific practice skills on the development of the working relationship with clients, and in turn, the impact of this relationship on a number of outcome measures.

Working relationship was defined as rapport ("I get along with my social worker"), trust ("I can tell my social worker anything on my mind"; "I can share my mistakes and failures as well as my successes with my social worker") and caring ("My social worker cares as much about me as he/she cares about my children"; "My social worker is here to help me not just to investigate me"). Outcome measures included client satisfaction with the social worker and case outcomes (e.g., number of days in care, court determinations, etc.).

This study also included examination of the impact of race on practice since a number of families in the study were from Canadian Aboriginal tribes while their workers were mostly Caucasian Canadians. Findings suggested that inter-cultural barriers could be overcome in practice when social workers effectively used a number of the interactional skills. Of particular importance was the client perception of the worker as sharing his or her own feelings. As one client commented, writing on her questionnaire: "I like my social worker. She isn't like a social worker but was more like a real person." As pointed out earlier, this was a key element in the Interactional Model as compared to the dichotomy between personal and professional widely taught in the Medical Model.

In addition, a significant cut in the number of Family Support Workers (600) providing preventive services to families was implemented by the Provincial Ministry during the course of this study. The cuts were implemented in different regions over time. We were able to track the impact of the cuts on such factors as the number of children taken into care in the region, how long they remained in care, and if they were returned home. Data analysis suggested that cost savings through the cuts in staff may well have been offset by significant increases in the number of children going into and staying longer in foster or residential care.

It was in this study that the Interactional Model concept of the importance of the parallel process was tested. A central tenant of the model is that the core skills of the helping process are important in all helping relationships including supervision and management. The use of these skills would be guided by the specific role of the helping professionals. For example, clarifying one's role and clarifying the purpose of the 
engagement would be important in the beginning phase in all professional relationships; however, the purpose and role of supervision would be significantly different than in direct practice.

Thus, it was possible to construct and test questionnaires for each of the levels of the study - executives, managers, supervisors, line workers and parents and explore the same skills and the working relationship for each. The specific wording was adapted to reflect the study population: for example, "I can tell my social worker anything on my mind" would be modified to "I can tell my supervisor anything on my mind." The finding of the study supported, among other findings, an association between the worker's perception of support from the supervisor and the resulting client's perception of support from the social worker. In other words, how a supervisor supervised had an impact on how social workers dealt with their clients. In turn, this could impact how parents responded to their children.

I published a complete report of the study in 1990 in a book entitled Interactional Social Work Practice: Toward an Empirical Theory. Using Causal Path Modeling techniques (Lisrel) I viewed the model as describing "Person, in Interaction, in Context over Time.” This was an effort to construct and test a holistic model that included variables such as client background, stress, motivation and support as well as worker background, stress, motivation and attitudes. Organizational context and supervision were examined as they impacted workers' practice. The impact of socio-economic context on the client was also modeled.

While the large sample was still too small to create one statically valid causal path model containing all of the variables, sub-models were created and examined. The effort was to determine how these complex variables affected the working relationship and the outcomes with a view toward determining the percent of the impact on the outcome variance. For example, how much did the social worker's education and skill impact the working relationship with the client and through the relationship the outcome measures of the study. In another example, what was the contribution of the client's socio-economic status, motivation, stress, etc. to the working relationship and, in turn, to the client outcomes? How much did these client variables directly impact the outcomes?

\section{Phase 10: Dissemination of the Interactional Model Through the Use of Videotaping}

Returning to my time at McGill and the University of British Columbia and to my friendship with the Director of the McGill Instructional Communication Center, I was able to use videotaping as a potent tool for communication of the model to the field. ${ }^{14}$ In 1975 a series of videotapes titled: The Helping Process in Social Work: Theory, Practice and Research were produced at McGill as was a video of Bill Schwartz in conversation with students entitled, "Private Troubles and Public Issues - One Social Work Job or Two." In this video Bill made the case for the social worker's responsibility, using a

\footnotetext{
${ }^{14}$ Many of these videos are now available as DVDs through Insight Media, "Justin Baer" < justin@insightmedia.com>, 800-233-9910)
} 
phrase from C. Wright Mills, not only for the client's "private troubles” but also for the "public issues" that impacted the client.

During my first year at the University of British Columbia I co-led a married couples group at the University's Health Science Center video camera-equipped meeting room. With the clients' permission, all 21 sessions were videotaped. The first session and the eighteenth session were selected for editing and use as training tapes. With the clients' additional permission, after viewing the two tapes following the last session, these programs were edited at McGill. Both the first and the eighteenth sessions were particularly illustrative of the mutual aid model and the role of the co-leaders in conducting a group within the framework of the Interactional Model.

The use of social work produced videotapes for teaching in social work was innovative at that time. The program committee for the Council on Social Work Education's annual meeting that year decided to play around the clock all of the produced tapes through the conference hotel's internal video system so that they could be viewed in a meeting room as well as in each of the participants' hotel rooms. I have no doubt that this event significantly increased interest in the Interactional Model. There was wide distribution of the programs at that time, and for some programs, a continued interest in their use today.

Additional programs were produced in 1980 (The Skills of Helping), 1983 (Core Skills for Field Instructors), 1988 (The Dynamics and Skills of the Middle Phase of Practice, in collaboration with my colleague Alex Gitterman) and in 1990 (Social Work Practice: An Interactional Approach). In 1994, while teaching at Boston University, a series of programs titled, "Teaching About Practice and Diversity: Content and Process in the Classroom and Field" were produced with my BU colleague Cassandra Clay and were (and still are) distributed by the Council on Social Work Education. ${ }^{15}$ These also were widely used as social work education searched for ways of addressing inter- and intra-cultural issues in practice and social work education further disseminating the Interactional Model framework.

Finally, recognizing that the dynamics of classroom teaching and that the concepts of the Interactional Model were just as relevant for education, where my research began in the 1970s, I have led or co-led workshops on classroom teaching for over 20 years at the Annual Meetings of the Council on Social Work Education attended by hundreds of practice faculty. Recognizing that "more is caught than taught," I presented a model for new and experienced faculty on how to conduct their classes in a manner that demonstrated good practice through the teaching role and mutual aid possibilities in a social work practice class.

In my final year of full-time teaching at the University at Buffalo, I led a year-long monthly workshop for faculty and doctoral students on the same topic. These sessions were videotaped and seven one-hour sessions edited and indexed (according to the topic). This collection of programs was produced and made available for free viewing or

\footnotetext{
${ }^{15}$ Available on the CSWE Website (www.cswe.org).
} 
downloading on the School's Web site (http://www.socialwork.buffalo.edu/facstaff/ skills dynamics.asp).

\section{Where Does the Paradigm Shift Stand Now?}

I have tried to share my personal and professional life experiences over a period of 52 years as a practitioner, researcher and educator, and to tie these experiences to what I believe has been an evolving shift in paradigms from the Medical Model to the Interactional Model. I was not alone in attempting to influence this paradigm shift and many others have contributed to extending the work started by Bill Schwartz. What I take from my experience is that it is possible for elements of a paradigm to change even if the paradigm itself does not.

For example, the Interactional Model led to an emphasis on operationalizing social work interventions and researching the process instead of just focusing on outcomes. Similar work was done, for example, by Truax (1966) with his emphasis on the Rogerian models of empathy, warmth and genuineness in-group psychotherapy. However, the medical model paradigm involving the three stage process - study, diagnosis and treatment - still guides practice in this area.

In another example, social systems theory has been widely integrated into helping models with an understanding that the client (or family, group or community) must be understood in a dynamic interaction within the system and with the environment; however, the interaction between the social worker and the client is not necessarily viewed in the same way.

The psychotherapeutic concept of being genuine is a step toward integrating the personal and professional selves; however, I still meet hundreds of social workers (and other professionals) in workshops or presentations who tell me that the concept of the worker sharing his or her feelings is refreshingly different from their current or recent past education. The use of spontaneity and "trusting their feelings" are also cited as welcome ideas but contrary to the model shared in their professional training or in their supervision. Others indicate that they were taught the Interactional Model in the MSW or BSW program; however, it may not have been specifically named nor the paradigm switch identified.

The recent emergence of Evidenced-Based Practices (EBP), such as Solution Focused, Cognitive-Behavioral Treatment and Motivational Interviewing, offer mixed evidence of a shift. On the one hand they are all very much concerned with process between the helping professional and the client. An example would be the key concept in Motivational Interviewing of recognizing that clients may be in a "pre-contemplation" stage, and describing interventions that respond to this reality. On the other hand, fairly rigid protocols associated with these EBPs may have restricted the ability of helping professionals to respond spontaneously and with their own emotions, even their own words, when interacting with a client. This results in a science that restricts art rather than encourages its expression, reinforcing the false dichotomy between science and art. I suspect this contributes to the concern, raised in publications of the National Institutes of 
Health (NIH) about the lack of "sustainability" when EBPs are introduced into agency practices.

So I conclude this description of my personal and professional journey with a mixed assessment of where we are in the paradigm shift. A recent positive event has been my receiving the Council on Social Work Education's Significant Lifetime Achievement Award. I believe this represents recognition of the work I have done in the development of the Interactional Paradigm. When I accept this award at the CSWE annual meeting, I will indicate that I believe I share it with William Schwartz. Certainly the process has moved further along, which is encouraging; however, I share my concern that we may not have gone far enough. A complete paradigm shift is difficult to accomplish and takes significant time and effort. We need also to recognize that for some professionals and educators the earth remains the center of the universe and the old lady never becomes the young lady.

\section{References}

Alinsky, S. (1971). Rules for radicals: A pragmatic primer for realistic radicals. New York, NY: Random House.

Amidon, E. J., \& Flanders, N. (1963). The role of the teacher in the classroom. Minneapolis, MN: Paul S. Amidon and Associates.

Brager, G., \& Holloway, S. (1978). Changing human service organizations: Politics and practice. New York, NY: Free Press.

Cloward, R., \& Ohlin, L. (1960). Delinquency and opportunity: A theory of delinquent gangs. Glencoe, IL: Free Press.

Fischer, J. (1973). Is casework effective? A review. Social Work, 18, 5-20.

Germain, C. B., \& Gitterman, A. (1980). The life model of social work practice: Advances in theory and practice. New York, NY: Columbia University Press.

Germain, C. B., \& Gitterman, A. (1996). The life model of social work practice: Advances in theory and practice ( ${ }^{\text {nd }}$ ed.). New York, NY: Columbia University Press.

Gitterman, A., \& Shulman, L. (Eds.). (1986). The legacy of William Schwartz: Group practice as shared interaction. New York, NY: Routledge. Also published as Social Work with Groups, 8(4).

Kuhn, T. S. (1962). The structure of scientific revolutions. Chicago, IL: The University of Chicago Press.

Papell, C., \& Rothman, B. (1966). Social groupwork models: Possession and heritage. Journal of Social Work Education, 2(2), 66-77.

Phillips, H. U. (1957). Essentials of social group work skill. New York, NY: Association Press. 
Pincus, A., \& Minahan, A. (1973). Social work practice: Model and method. Itasca, IL: F. E. Peacock.

Rosenberg, M. (1968). The logic of survey analysis. New York, NY: Basic Books.

Schwartz, W. (1961). The social worker in the group. In New perspectives on services to groups: Theory, organization, and practice (pp. 7-34). New York, NY: National Association of Social Workers.

Schwartz, W. (1986). The group work tradition and social work practice. In A. Gitterman \& L. Shulman (Eds.), The legacy of William Schwartz: Group practice as shared interaction (pp. 7-28). New York, NY: Routledge. Also published in Social Work with Groups, 8(4), 17-28.

Shulman, L. (1968). A casebook of social work with groups. New York, NY: Council on Social Work Education. (Published in Swedish by Student Litteratur, 197l; French Edition published by Association Nationale des Assistantes Sociales, 1977).

Shulman, L. (1969). Social system theory in field instruction. In G. Hearn (Ed.), Social systems theory in social work education (pp. 339-349). New York, NY: The Council on Social Work Education.

Shulman, L. (1979). The skills of helping individuals and groups. Itasca, IL: F. E. Peacock.

Shulman, L. (1986). The dynamics of mutual aid. Social Work with Groups, 8(4), 51-60.

Shulman, L. (1990). Interactional social work practice: Toward an empirical theory. Itasca, IL: F. E. Peacock.

Shulman, L. (2012). The skills of helping individuals, families, groups and communities ( $7^{\text {th }}$ ed.). Belmont, CA: Brooks/Cole.

Shulman, L., \& Buchan, W. (1982). The impact of the family physician's communication, relationship and technical skills on patient compliance, satisfaction, reassurance, comprehension and improvement. Vancouver, BC: The University of British Columbia.

Simon, A. (Ed.). (1967). Mirrors for behavior: An anthology of classroom observation instruments. Philadelphia, PA: Temple University, Center for the Study of Teaching, Research for Better Schools.

Specht, H., \& Courtney, M. E. (1993). Unfaithful angels. New York, NY: Free Press.

Truax, C. B. (1966). Counseling and psychotherapy: Process and outcome. Fayetteville, AR: University of Arkansas, Arkansas Rehabilitation Research and Training Center.

\section{Author note}

Address correspondence to: Lawrence Shulman, PO Box 1651, Grantham, NH 037531651. Email: shulman@buffalo.edu 


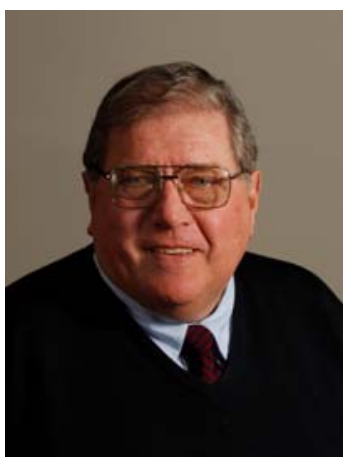

Lawrence Shulman, M.S.W., Ed.D., is a retired Professor and former Dean at the University of Buffalo School of Social Work. He has been a social work practice educator for over forty years, maintaining a pro-bono practice with at least one social work group each year. He has done extensive research on the core helping skills in social work practice, supervision, and child welfare. In addition to his many awards, he is a 2014 recipient of the Council on Social Work Education's Significant Lifetime Achievement Award and was recently honored by his selection to the Columbia University School of Social Work's Alumni Hall of Fame. He has been a widely used consultant and trainer in many areas of social work practice and education nationally and internationally, including Canada, Norway, Hong Kong, Bermuda, and Australia. He has published numerous articles and monographs on direct practice and is the author or co-editor of eight books, many of which are referenced in this article. 